\title{
Remote Teamwork Management of NORSE During the COVID-19 Lockdown
}

Alberto Cossu, MD*, Tommaso Lo Barco, MD*, Francesca Darra, MD, Elena Fontana, MD, Elena Fiorini, MD, Martina Marangone, Paolo Biban, MD, Bernardo Dalla Bernardina, MD, and Gaetano Cantalupo, MD

Neurology: Clinical Practice April 2021 vol. 11 no. 2 e170-e173 doi:10.1212/CPJ.0000000000001027
Correspondence

Dr. Cantalupo

gaetano.cantalupo@univr.it

\begin{abstract}
New-onset refractory status epilepticus (NORSE) is rare condition, and sharing knowledge is vital in its management, based on strict collaboration between multiple specialists, continuous EEG (c-EEG) monitoring, and prompt therapy modification. The coronavirus disease 2019 (COVID-19) pandemic challenged many of these established practices because of "social distancing” measures, making it necessary to work around physical restrictions. We report a case of a 10-year-old with NORSE admitted in a pediatric intensive-care unit and monitored with c-EEG and amplitudeintegrated EEG. The monitoring interface was livestreamed using videoconference web-based platforms allowing remote viewing. Multiple daily web meetings took place between team members, where real-time therapy response was evaluated and confronted with medium-term trends in the epileptic activity, dictating further treatment and diagnostic steps. In addition to the known use of telemedicine in chronic conditions, we report how its use can be exploited to treat urgent conditions such as NORSE. By taking advantage of new tools and virtual environments, we were able to share treatment and diagnostic decisions and guarantee real-time therapy adjustments and a coherent course in treatment despite restrictions necessary for the COVID-19 pandemic. The constant specialist monitoring and the coherent and on-time communication of the patient's condition relieved the family stress, usually complained in these situations.
\end{abstract}

New-onset refractory status epilepticus (NORSE) is defined as status epilepticus arising in a patient without previous knowledge of epilepsy or epileptic syndromes, refractory to the first treatment and to a second appropriate antiseizure medication. ${ }^{1}$ The patients are admitted in intensive care units (ICUs) and, in nonconvulsive status epilepticus (NCSE), need continuous EEG (c-EEG) monitoring. ${ }^{2}$ Multidisciplinary approach is often mandatory, and therapeutic decisions are team-oriented. ${ }^{3}$

The global pandemic caused by severe acute respiratory syndrome coronavirus 2 produced a profound impact on the workflow of many healthcare workers. ${ }^{4}$ In high infections areas, such as Veneto, Italy, nonurgent care was postponed or performed remotely, and professionals were encouraged not to share workspaces, to avoid hazardous contacts, with the aim of slowing the spread of the pandemic. ${ }^{5}$

\section{MORE ONLINE}

COVID-19 Resources

For the latest articles, invited commentaries, and blogs from physicians around the world NPub.org/COVID19

We report a case of NORSE whose management, including EEG-guided therapeutic decisions, was remotely shared between different specialists because of "social distancing" measures in northern Italy during the coronavirus disease 2019 (COVID-19) pandemic.

*These authors contributed equally to the manuscript.

Child Neuropsychiatry (FD, TLB, FD, GC), Department of Surgical Sciences, Dentistry, Gynecology and Pediatrics, University of Verona; Clinical and Experimental Medicine PhD Program (TLB), University of Modena and Reggio Emilia; Child Neuropsychiatry Unit (FD, E. Fontana, E. Fiorini, MM, GC), and Pediatric Intensive Care Unit (PB), University-Hospital of Verona; and Center for Research on Epilepsies in Pediatric Age (CREP) (BDB), Verona, Italy.

Funding information and disclosures are provided at the end of the article. Full disclosure form information provided by the authors is available with the full text of this article at Neurology.org/cp. 


\section{Case}

A 10-year-old girl without a history of epilepsy was brought to our pediatric emergency room for repeated vomiting and progressive somnolence. During the evaluation, she had a convulsive seizure, followed by aphasia and progressive awareness impairment. EEG documented a focal NCSE with seizures originating from temporal lobes. She was admitted to the pediatric ICU (PICU) and despite multiple antiseizure medications, focal seizures persisted with increasing frequency. Sequential sedative drugs were challenged, obtaining only transient results.

CSF analysis did not detect any microbiological agent nor neuronal surface autoantibodies. Brain MRI were negative up to day 19, when a fourth MRI showed multifocal minute cortical T2 hyperintensities.

Because of the diagnostic suspicion of seronegative autoimmune encephalitis, she was treated with high-dose intravenous immunoglobulin, corticosteroids, and repeated plasma-exchange procedures.

Because of restrictions suggested by Regione Veneto for the COVID-19 pandemic, since March 2020, our unit limited the clinical activity to urgent cases only. Subsequently, simultaneous presence of more than 1 team member was limited to few hours per day; 1 child neurologist on-call was guaranteed every day for urgent cases, with 12 -hour shifts.

Since the admission in the PICU, the patient underwent continuous video-EEG (VEEG) recording, visualized on the portable recording equipment's screen as conventional VEEG (video and raw traces) flanked by multichannel amplitudeintegrated EEG (aEEG) trends. The portable EEG recording equipment (all-in-one touchscreen PC mounted on a pole cart; BrainQuick ICU Line, Micromed S.p.A., Veneto, Italy) at the patient's bedside was connected through an ethernet cable to the hospital network. Once every 12 hours, the VEEG data were archived into a dedicated server. Archived data were accessible for offline review and analysis from workstations within the hospital and from home via the digital workspace platform Citrix Workspace (Citrix Systems, Inc., Fort Lauderdale, FL), implemented with the BrainQuick software (Micromed S.p.A.). BrainQuick software also allows an online remote review of the ongoing recording. Restricted remote access to Citrix Workspace was provided by hospital administration to individual physicians via personal account (ID code and alphanumeric password with 3 months expiration period), allowing safe and chronicled access to clinical data and licensed software.

The visual interface of the monitoring VEEG equipment was livestreamed via a web-based videoconference platformprovided by hospital administration, in line with privacy guidelines-that allows participants to livestream the content of their monitor and communicate via video, audio, and written chat (Google Meet: support.google.com/a/answer/ 7582940\#counterabuse). Using this platform, physicians could view the feed in real-time 24 hours/ 7 days via PC, tablet, or smartphone from other hospital departments or from home.

Scheduled meetings took place twice a day on Google Meet platform among child neuropsychiatry unit specialists, residents attending the unit, and a senior expert (B.D.B.).

During meetings, ongoing VEEG/aEEG data were viewed live and archived material was reviewed sharing a second monitor. Considering trends in the epileptic activity, treatment options and therapeutic steps were outlined. Updates regarding auditions with patient's parents were discussed, allowing a shared communication approach among physicians.

Multiple daily meetings with the PICU team served to discuss diagnostic and therapeutic possibilities. PICU personnel on night or weekend shifts was instructed to detect changes in aEEG that could represent seizures and warn child neurologist on-call who could remotely review raw EEG and suggest therapy modification. Furthermore, EEG activity evoked by stimulation, administered by PICU personnel under remote instruction of the neurologic team, was taken into account in real-time to evaluate therapy response and subsequent treatment steps.

Seizures progressively became less frequent after the seventh plasma exchange procedure, and the patient was weaned from ventilation on day 28 . Seizures stopped 2 months after the admission, and she was discharged on day 70 .

\section{Discussion}

NORSE is often associated with unfavorable outcome. ${ }^{2}$ Patients fail to respond to first- and second-line therapies, requiring continuous intravenous anesthetic drugs to control ongoing seizures. ${ }^{3}$ They need to be admitted in ICU, where the length of stay can last several weeks or months. Over this period, the management of patients with NORSE is multifaceted.

In NCSE, seizure burden correlates with increased risk of poor outcome in children. ${ }^{6}$ Continuous EEG monitoring is indispensable to recognize nonconvulsive seizures, rapidly detect seizures worsening, and avoid delay in adequate therapeutic modifications. ${ }^{7}$

The COVID-19 pandemic affected the workflow of many healthcare workers; in our case, nonurgent care was postponed and the presence of physicians in hospitals was encouraged to be limited.

Remote VEEG/aEEG monitoring allowed real-time analysis from different locations within the hospital, making the presence of clinical neurophysiologist on patient bedside unnecessary. Furthermore, remote VEEG/aEEG monitoring was available on domestic electronic devices of authorized 


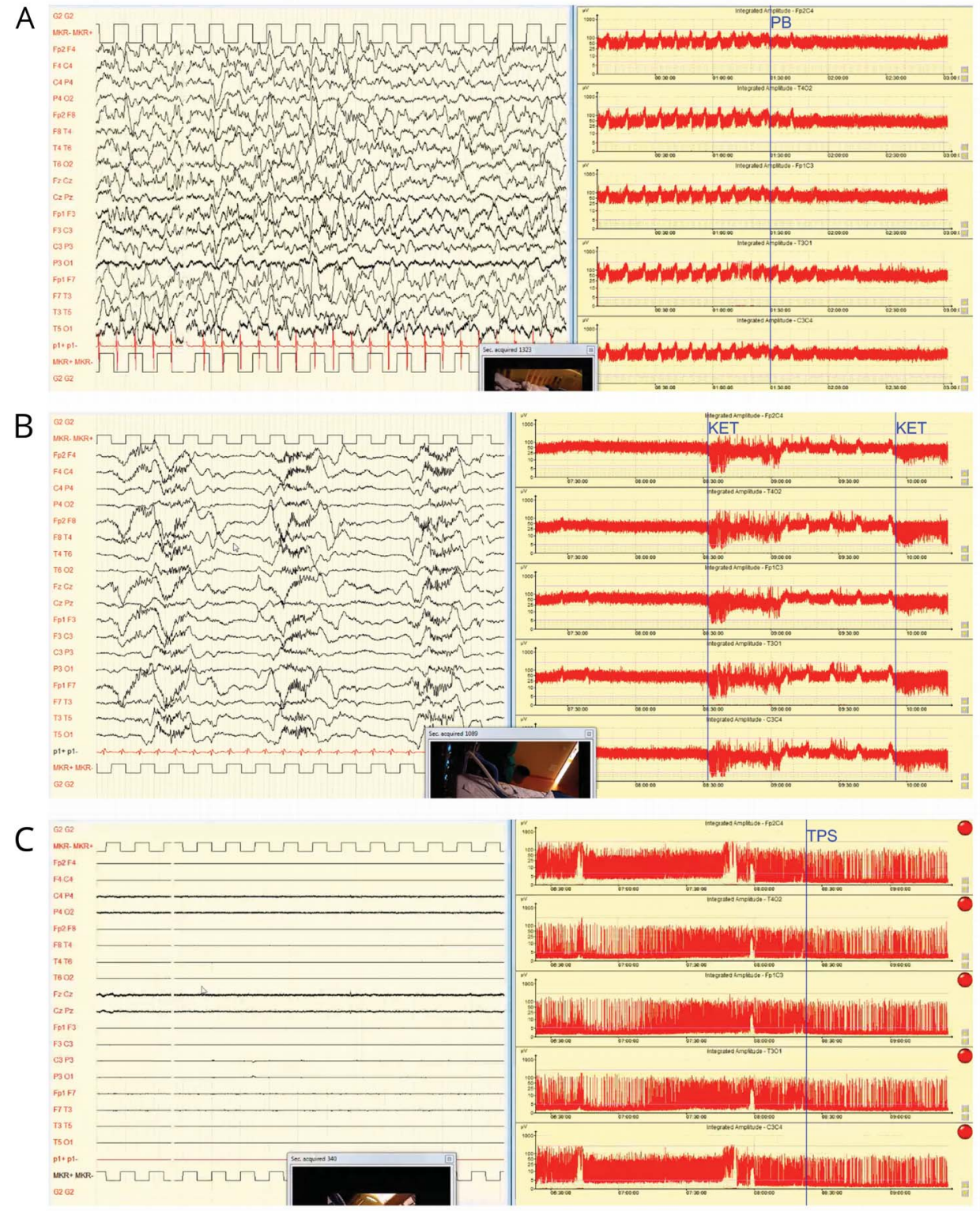

The image shows a cropped version of the streamed monitoring interface, with the live raw EEG data on the left-hand side, showing 20 seconds of recording, and a multichannel aEEG interface on the right-hand side displaying roughly 3 hours of monitoring. In the streaming interface, a smaller video feed of the patient was available to evaluate clinical manifestation of seizure or recognize artifact. (A) Third day of admission in the PICU: the aEEG documents the periodic recurrence of diffuse seizures, roughly 7 in the first hour. The seizures on aEEG are characterized by the concomitant increase of the maximum and minimum amplitude in the corresponding bipolar channels. After 1 hour and 30 minutes (blue vertical line), a bolus of phenobarbital (PB) (100 mg) is administered, followed by a decrease of the seizure frequency, with 4 seizures with a progressively longer interval. (B) Fourth day of admission in the PICU: the aEEG initially shows a continuous high amplitude activity (high max. and min. amplitude). After a first bolus and an increase of the ketamine infusion (50 mg followed by $20 \mu \mathrm{g} / \mathrm{kg} / \mathrm{min}$ ), indicated by the first blue line (KET), the activity is characterized by an initial response, followed by the recurrence of seizures. After a second $50 \mathrm{mg}$ bolus (second blue line) and an increase of the ketamine infusion rate $(25 \mu \mathrm{g} / \mathrm{kg} / \mathrm{min})$ the activity is characterized by a fluctuating and discontinuous pattern. (C) Sixth day of admission in the PICU: in the first hour, the activity has a burst-suppression pattern, with a continuously low maximum amplitude, interloped with short, and high amplitude bursts. In the following 90 minutes, the activity becomes continuous with a progressively higher maximum amplitude and the recurrence of diffused seizures. On the right central electrode (and therefore on aEEG Fp2-C4 and C3C4 channels), the trace is disturbed by a continuous artifact. The blue line (TPS) indicates a $60 \mathrm{mg}$ bolus thiopental, followed by increase in the infusion velocity $(10 \mathrm{mg} / \mathrm{kg} / \mathrm{h})$, after which the activity returns to a burst-suppression pattern. aEEG = amplitude-integrated EEG; $P I C U$ = paediatric intensive care unit; $V E E G$ = video EEG.

physicians and residents, with a possibility to live comment through text chat and microphone. This brought several additional benefits.

EEG features can vary radically during NCSE, and electroclinical targets need to be remodulated accordingly. ${ }^{7}$ Furthermore, "individual members of the medical teams may have differing knowledge of the disorder and differing views on treatment goals, including when to stop or withhold treatment."1 In our case, despite the child neurologist's presence limited to the on-call specialist, electroclinical course could be followed daily by all team members using remote EEG. Medical decisions, goals, and potential future treatment options were discussed and shared during scheduled online meetings. Besides minimizing handover errors during shift changes, ${ }^{8}$ this allowed to pursue a coherent longterm therapeutic strategy, avoiding decisions to be taken by the on-call child neurologist solely on the basis of latest hours of EEG recordings.

Moreover, NORSE is an uncommon condition, and each specialist has usually treated a limited number of patients, so "sharing knowledge by participating in meetings, inviting outside specialists, and fostering multidisciplinary communication and collaboration is vital."3 A senior expert was invited at online meetings, being able to see EEG traces remotely and participate to decision-making.

In addition, child neuropsychiatry residents were admitted joining online meetings. Pediatric NORSE is an extremely rare 
condition, ${ }^{2}$ and our case constituted a unique occasion of casebased learning joined with a hands-on approach that could have been lost without this "telemedicine" management.

In NORSE cases, the care is usually performed by 2 different teams: the ICU team and the neurology team, and a constant cooperation is crucial. ${ }^{1}$ Besides multiple meetings on weekdays, coupling VEEG, aEEG, and remote monitoring allowed a strict collaboration with the PICU team during night shifts and weekends. Because seizures were identifiable on aEEG (figure), PICU physicians were instructed to suspect seizures and notify the neurologist on-call, who could remotely confirm changes in seizure frequency, adjust treatment quickly, and monitor the effect.

The clinical uncertainty associated with NORSE can lead to specific communication issues between physicians and families who have to be constantly updated to be included in the decision-making process. ${ }^{1-3}$ Information given to families need to be coherent and coordinated among all members of the team. ${ }^{1,3}$ In our hospital, during the COVID-19 pandemic, the presence of 1 child neurologist per day for urgent cases was planned on 12-hour shifts. Consequently, all team members had to interface with the patient's family. To guarantee nonambiguous communication, a shared strategy was outlined during online daily meetings. The constant monitoring of our team, even if not physically present, was known to the patient's family and was a source of reassurance of the continuous care of the patient's conditions.

The possibility to share clinical material and information remotely allowed our team to guarantee the best possible care, exploiting new media and virtual environments to share decision-making in a multidisciplinary manner. The streaming and sharing of EEG traces/trends and clinical decisions had also great educational value for residents and young fellows who were able to witness clinical practice in real-time.

In many ways, the COVID-19 pandemic will represent a turning point for modern medicine. This new status quo has brought to mass attention available instruments that could lead to long-lasting changes healthcare practice. ${ }^{9}$

Regarding epilepsy, efforts have been made to implement telemedicine for the long-term care of epileptic patients, with particular attention to rural or low resources areas, where specialist to patient ratio is low. ${ }^{10}$ Our report shows how telemedicine can be implemented to treat urgent and severe condition such as NORSE and NCSE, playing a vital role in guaranteeing a high level of care.

\section{Study Funding}

No targeted funding reported.

\section{Disclosure}

The authors report no disclosures relevant to the manuscript. Full disclosure form information provided by the authors is available with the full text of this article at Neurology.org/cp.

\section{Publication History}

Received by Neurology: Clinical Practice August 17, 2020. Accepted in final form October 30, 2020.

Appendix Authors

\begin{tabular}{|c|c|c|}
\hline Name & Location & Contribution \\
\hline Alberto Cossu, MD & $\begin{array}{l}\text { Verona, } \\
\text { Italy }\end{array}$ & $\begin{array}{l}\text { Collected and interpreted clinical } \\
\text { data and wrote the first draft and } \\
\text { revised the manuscript }\end{array}$ \\
\hline Tommaso Lo Barco, MD & $\begin{array}{l}\text { Verona, } \\
\text { Italy }\end{array}$ & $\begin{array}{l}\text { Collected and interpreted clinical } \\
\text { data and wrote the first draft and } \\
\text { revised the manuscript }\end{array}$ \\
\hline Francesca Darra, MD & $\begin{array}{l}\text { Verona, } \\
\text { Italy }\end{array}$ & $\begin{array}{l}\text { Collected and interpreted } \\
\text { clinical data }\end{array}$ \\
\hline Elena Fontana, MD & $\begin{array}{l}\text { Verona, } \\
\text { Italy }\end{array}$ & $\begin{array}{l}\text { Collected and interpreted } \\
\text { clinical data }\end{array}$ \\
\hline Elena Fiorini, MD & $\begin{array}{l}\text { Verona, } \\
\text { Italy }\end{array}$ & $\begin{array}{l}\text { Collected and interpreted } \\
\text { clinical data }\end{array}$ \\
\hline Martina Marangone & $\begin{array}{l}\text { Verona, } \\
\text { Italy }\end{array}$ & $\begin{array}{l}\text { Collected and interpreted } \\
\text { clinical data }\end{array}$ \\
\hline Paolo Biban, MD & $\begin{array}{l}\text { Verona, } \\
\text { Italy }\end{array}$ & $\begin{array}{l}\text { Collected and interpreted } \\
\text { clinical data }\end{array}$ \\
\hline $\begin{array}{l}\text { Bernardo Dalla } \\
\text { Bernardina, MD }\end{array}$ & $\begin{array}{l}\text { Verona, } \\
\text { Italy }\end{array}$ & $\begin{array}{l}\text { Collected and interpreted } \\
\text { clinical data }\end{array}$ \\
\hline Gaetano Cantalupo, MD & $\begin{array}{l}\text { Verona, } \\
\text { Italy }\end{array}$ & $\begin{array}{l}\text { Collected and interpreted clinical } \\
\text { data, wrote and revised the } \\
\text { manuscript, and prepared the } \\
\text { figure }\end{array}$ \\
\hline
\end{tabular}

\section{References}

1. Gofton TE, Wong N, Hirsch LJ, Hocker SE. Communication challenges: a spotlight on new-onset refractory status epilepticus. Mayo Clin Proc 2019;94:857-863.

2. Sculier C, Gaspard N. New onset refractory status epilepticus (NORSE). Seizure 2019;68:72-78.

3. Gaspard N, Hirsch LJ, Sculier C, et al. New-onset refractory status epilepticus (NORSE) and febrile infection-related epilepsy syndrome (FIRES): state of the art and perspectives. Epilepsia 2018;59:745-752.

4. Ohannessian R, Duong TA, Odone A. Global telemedicine implementation and integration within health systems to fight the COVID-19 pandemic: a call to action. JMIR Public Heal Surveill 2020;6:e18810.

5. Coronavirus. Il veneto riorganizza attivita' sanitarie per preservare posti letto di terapia intensiva [internet]. 2020. Available at: regione.veneto.it/article-detail? articleId=4377038. Accessed August 10, 2020.

6. Payne ET, Zhao XY, Frndova H, et al. Seizure burden is independently associated with short term outcome in critically ill children. Brain 2014;137:1429-1438.

7. Herman ST, Abend NS, Bleck TP, et al. Consensus statement on continuous EEG in critically ill adults and children, part II: personnel, technical specifications, and clinical practice. J Clin Neurophysiol 2015;32:96-108.

8. O'Byrne WT, Weavind L, Selby J. The science and economics of improving clinical communication. Anesthesiol Clin 2008;26:729-744.

9. Nouri SS, Khoong EC, Lyles CR, et al. Addressing equity in telemedicine for chronic disease management during the COVID-19 pandemic. NEJM Catal 2020;2020:1-13.

10. Williams JA, Cisse FA, Schaekermann M, et al. Smartphone EEG and remote online interpretation for children with epilepsy in the Republic of Guinea: quality, characteristics, and practice implications. Seizure 2019;71:93-99. 


\section{Neurology ${ }^{\circ}$ Clinical Practice}

Remote Teamwork Management of NORSE During the COVID-19 Lockdown

Alberto Cossu, Tommaso Lo Barco, Francesca Darra, et al.

Neurol Clin Pract 2021;11;e170-e173 Published Online before print December 3, 2020

DOI 10.1212/CPJ.0000000000001027

This information is current as of December 3, 2020

Updated Information \&

Services

References

Subspecialty Collections

Permissions \& Licensing

Reprints including high resolution figures, can be found at:

http://cp.neurology.org/content/11/2/e170.full.html

This article cites 9 articles, 0 of which you can access for free at: http://cp.neurology.org/content/11/2/e170.full.html\#\#ref-list-1

This article, along with others on similar topics, appears in the following collection(s):

COVID-19

http://cp.neurology.org//cgi/collection/covid_19

Information about reproducing this article in parts (figures,tables) or in its entirety can be found online at:

http://cp.neurology.org/misc/about.xhtml\#permissions

Information about ordering reprints can be found online: http://cp.neurology.org/misc/addir.xhtml\#reprintsus

Neurol Clin Pract is an official journal of the American Academy of Neurology. Published continuously since 2011, it is now a bimonthly with 6 issues per year. Copyright () 2020 American Academy of Neurology. All rights reserved. Print ISSN: 2163-0402. Online ISSN: 2163-0933.

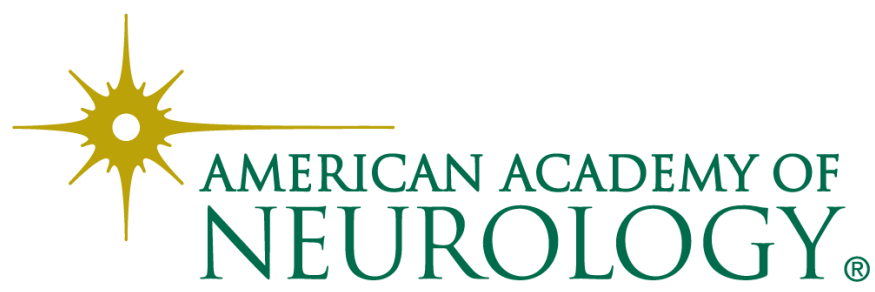

